\title{
Conhecimento organizacional em escolas de governo: um estudo comparado
}

\author{
Anderson Macedo de Jesus \\ United Nations Development Programme \\ Luciana Mourão \\ Universidade Salgado de Oliveira
}

\begin{abstract}
Como reflexo de uma tendência que tem ganhado importância crescente nas organizações públicas, privadas e não governamentais do Brasil e do mundo, a temática gestão do conhecimento motivou a realização desta pesquisa, cujo foco imediato é fornecer subsídios para auxiliar organizações públicas como escolas de governo em seus processos de desenvolvimento de conhecimento organizacional. Este conhecimento é criado mediante a interação dos conhecimentos tácito e explícito. A interação entre eles pode ser verificada por meio de quatro conversões, as quais formam um ciclo do conhecimento organizacional: a socialização, a externalização, a combinação e a internalização. O estudo em questão visa apresentar um conjunto de critérios representantes do ciclo de desenvolvimento do conhecimento organizacional e, mediante análise comparada entre sete escolas de governo internacionais e uma nacional, a Fundação Escola Nacional de Administração Pública (Enap), elaborar o desenho de uma estrutura organizacional que maximize o desenvolvimento do conhecimento organizacional em escolas de governo.
\end{abstract}

Palavras-chave: escolas de governo; análise comparada; conhecimento organizacional; gestão do conhecimento; capital humano.

Conocimiento organizacional en escuelas del gobierno: un estudio comparado

Como reflejo de una tendencia que ha ganado importancia creciente en las organizaciones públicas, privadas y no gubernamentales de Brasil y del mundo, la temática gestión del conocimiento motivó la realización de esta investigación, cuyo enfoque inmediato es proporcionar subsidios para auxiliar a organizaciones públicas como escuelas del gobierno en sus procesos de desarrollo de conocimiento organizacional. Este conocimiento se crea mediante la interacción de los conocimientos tácito y explícito. La interacción entre los mismos puede ser verificada por medio de cuatro conversiones, las cuales forman un ciclo del conocimiento organizacional: la socialización, la externalización, la combinación y la internalización. El estudio en cuestión tiene el objetivo de presentar un conjunto de criterios repre-

Artigo recebido em 19 nov. 2010 e aceito em 4 maio 2011.

Rev. Adm. Pública - Rio de Janeiro 46(4):939-68, jul./ago. 2012 
sentantes del ciclo de desarrollo del conocimiento organizacional y, mediante el análisis comparado entre siete escuelas del gobierno internacionales y una nacional, la Fundación Escuela Nacional de Administración Pública (Enap), elaborar el diseño de una estructura organizacional que maximice el desarrollo del conocimiento organizacional en escuelas del gobierno.

Palabras clave: escuelas del gobierno; análisis comparado; conocimiento organizacional; gestión del conocimiento; capital humano.

Organizational knowledge in schools of government: a comparison study

As a reflection of a trend that has gained increasing importance in public organizations, private and non governmental organizations in Brazil and the world, the issue led to Knowledge Management this research, whose immediate focus is to provide grants to help organizations public schools and government in their development processes knowledge organizational. This knowledge is created by interaction of tacit and explicit. The interaction between them can be verified by through four conversions, which form a cycle of organizational knowledge: a socialization, externalization, combination and internalization. This study aims to present a set of criteria representing the cycle of development of organizational knowledge and, through comparative analysis of seven schools International and one national government, the Escola Nacional de Administração Pública (Enap), draw up the design of an organizational structure that maximizes the development of organizational knowledge in government schools.

KEY WORDs: school of government; comparative analysis; organizational knowledge; management knowledge; human capital.

\section{Introdução}

A sociedade atual vem enfrentando transformações constantes marcadas pela abundância de informações e ritmos acelerados de inovações. Essas condições forçam as instituições públicas e privadas a atualizarem suas estruturas de conhecimento dos recursos humanos dentro do forte clima de incerteza que alguns autores denominam como Era do Conhecimento (Silva, 2004).

Os dados se tornaram um conjunto de fatos distintos e objetivos relativos a eventos que se transformam em informação, quando acrescido de contextualização, categorização, correção e condensação. Essa informação, quando acrescida de comparação, conexões e conversação, se transforma no mais importante ativo intangível da organização, o conhecimento (Davenport e Prusak, 1998; Edvinsson e Malone, 1998). À procura de novas alternativas para a melhoria da produtividade e da competitividade organizacional, as instituições procuram fazer o melhor uso de seus ativos tangíveis e intangíveis (conhecimentos tácito e explícito) para aumentar a vantagem competitiva no mercado. A gestão do conhecimento (GC) torna-se, portanto, o conjunto de processos e meios mais importante para criar, utilizar e disseminar conhecimento dentro de uma organização. Não há dúvida de que o atual ambiente organizacional intensifica a importância em adquirir e gerenciar o conhecimento humano e o aprendizado interativo contínuo (Colauto e Beuren, 2003). 
Neste cenário de dados, informações e conhecimentos que trafegam e se modificam rapidamente de um lugar para outro, as tecnologias de informação (TI) agora não só armazenam dados, muito pelo contrário, tornaram-se um importante canal facilitador da comunicação e/ou de transferência da informação (Silva, 2004).

De acordo com Marchand e Davenport (2004), os conceitos sobre GC concentram-se na parceria do capital humano com a tecnologia. Diante desse contexto de mudanças significativas no ambiente organizacional no mundo e diante das dificuldades enfrentadas pela Fundação Escola Nacional de Administração Pública (Enap) para melhorar seu cenário interno de GC na atual gestão de governo, o desenvolvimento de um estudo de caso foi proposto e efetuado na organização no ano de 2005 (Jesus, 2006).

Esse estudo de caso teve como intuito analisar o ciclo de desenvolvimento do conhecimento organizacional (entre os anos 2000 e 2005) na perspectiva adotada por Nonaka e Takeuchi (1997), no que diz respeito à interação dos conhecimentos tácito e explícito. ${ }^{1}$

Segundo Jesus (2006), três ocorrências importantes foram identificadas no estudo: 1) alta rotatividade do capital humano (funcionários) — provável causa da perda no processo de desenvolvimento do conhecimento organizacional (criação, divulgação e manutenção); 2) melhorias advindas da introdução das tecnologias de informação (TI) — viabilização do processo de gestão do conhecimento organizacional, diminuindo a perda de conhecimento em ambientes de grande rotatividade de capital humano; e 3) problemas nos processos organizacionais - em parte falhos por resistência do capital humano.

As ocorrências diagnosticadas no estudo de caso de Jesus (2006) inspiraram o desenvolvimento deste trabalho, que focou as duas primeiras ocorrências relatadas pelo autor e, portanto, teve como intuito discutir a importância das tecnologias de informação e dos processos organizacionais para um debate comparativo dentro da estrutura de oito renomadas "escolas de governo", ${ }^{2}$ sendo uma nacional e sete internacionais, ${ }^{3}$ responsáveis pela formação e capacitação de servidores públicos no mundo.

Os critérios identificados e analisados entre as escolas de governo serviram de base para configurar não um padrão ideal de escola de governo, no que diz respeito à gestão do conhecimento organizacional, mas um modelo que represente uma possível maximização dos

\footnotetext{
${ }^{1} \mathrm{O}$ conhecimento tácito possui uma natureza intuitiva e subjetiva que torna difícil a transmissão ou o processamento daquilo a ser compartilhado. Já o conhecimento explícito possui manuseio mais simples e concreto, ou seja, pode ser encontrado em forma de dados e de informações (Nonaka e Takeuchi, 1997).

${ }^{2}$ Para fins de análise utilizaremos a definição de Pacheco (2000) sobre escola de governo: "Assumimos como 'escola de governo' (...) aquelas instituições destinadas ao desenvolvimento de funcionários públicos incluídas no aparato estatal central (nacional ou federal) ou fortemente financiadas por recursos orçamentários (...)”.

${ }^{3}$ As escolas de governo internacionais pesquisadas foram: Instituto de Administração Pública (INA), de Portugal; Bundesakademie für öffentliche Verwaltung, da Alemanha, mais conhecido como Federal Academy of Public Administration; The Austrália and New Zealand School of Government, da Nova Zelândia e Austrália; European Institute of Public Administration, da União Europeia; John Kennedy School of Government, da Harvard University dos Estados Unidos da América; École Nationale d’Administration, da França; e o Instituto Nacional de la Administración Pública, da República Argentina.
} 
processos e meios utilizados para criar, utilizar e disseminar o conhecimento dentro de escolas de governo no mundo.

\section{Referencial teórico}

O uso da terminologia GC é polêmica. Marchand e Davenport (2004) reconhecem que há um grande componente de gestão da informação na GC e que grande parte do que se faz passar por GC é, na verdade, gestão da informação. Contudo, eles consideram que GC vai além da gestão da informação ao endereçar aspectos como a criação e o uso do conhecimento. Wilson (2002) examinou os conceitos atribuídos à GC e reafirmou toda a polêmica e controvérsia terminológica. Porém, apesar de toda a discussão a respeito do termo gestão do conhecimento, Alvarenga Neto (2005) concluiu que essa área tem surpreendido aqueles que apostaram em um modismo, pois a mesma tem se estabelecido como um consistente paradigma gerencial deste século.

Souto (2007) avalia que os fundamentos conceituais da gestão do conhecimento têm sido minados por uma combinação contraditória de paradigmas e ressalta que há também contradições entre a perspectiva teórica subjacente à gestão do conhecimento e sua operacionalização. Como forma de minimizar a possibilidade de a gestão do conhecimento se tornar um conceito "guarda-chuva", a autora sugere que suas abordagens incorporem uma perspectiva mais interpretivista, movimentando-se mais na direção de ser um instrumento capacitador e facilitador dos processos e práticas de construção de conhecimento e de informação.

Alvarenga Neto, Barbosa e Pereira (2007) apresentam um interessante ensaio teóricoprático que discute, a partir de intervenções na realidade brasileira, o uso do termo GC em contraposição à gestão de organizações da era do conhecimento. $\mathrm{O}$ artigo relata as motivações, concepções, práticas gerenciais, ênfases, métricas, indicadores e resultados de programas de GC e sugere que a expressão "gestão do conhecimento" seja ao mesmo tempo um paradoxo e uma impropriedade terminológica.

Uma premissa do trabalho de Alvarenga Neto, Barbosa e Pereira (2007) é que o conhecimento só existe na mente humana e no espaço imaginário entre mentes criativas em sinergia de propósitos. Fora deste contexto, os autores consideram que o conhecimento é visto como informação. Para eles, a GC ganha terreno a partir da compreensão de que sua terminologia é metafórica, uma vez que o conhecimento é inerente aos seres humanos e não se transfere ou se compartilha com facilidade ou espontaneidade. Assim, os autores ressaltam que grande parte do que se convenciona chamar GC é, na verdade, gestão da informação e a gestão da informação é apenas um dos componentes da GC, uma vez que esta última vai além da pura gestão da informação por incluir e incorporar outros aspectos, temas, abordagens e preocupações, como as questões de criação, uso e compartilhamento de informações e conhecimentos, além da criação de contextos organizacionais favoráveis.

Numa linha semelhante, Fachin e colaboradores (2009) apresentam uma interessante reflexão sobre o conhecimento e o ciclo que permite sua gestão. Para os autores: 
O conhecimento em si está nas pessoas, intrínseco a elas, e é no dia a dia de uma organização que se forma um ciclo constante de troca, onde uma pessoa transforma seu conhecimento em informação, registrando-a e divulgando-a, da mesma forma que assimila outras, criando um ciclo de compartilhamento evolutivo, onde dados, informação e conhecimento são trocados (Fachin et al., 2009:227).

De fato, tanto a informação quanto o conhecimento são relacionais, na medida em que dependem da transmissão de significados de forma dinâmica por intermédio das ações humanas (Vick, Nagano e Santos, 2009) e as inovações resultam na aplicação prática de novos conhecimentos e são respostas às mudanças enfrentadas pelas organizações no seu ambiente (Silva, 2007).

No que diz respeito especificamente à gestão do conhecimento, Teece (2000) destaca, três objetivos são fundamentais para caracterizar o movimento da gestão do conhecimento: (a) a criação de "depósitos" de conhecimento com informação externa (inteligência competitiva e melhores práticas) e interna (relatórios de pesquisas internas); além do conhecimento interno informal, como discussões em bases de dados; (b) o aprimoramento do acesso ao conhecimento, e com isso a reutilização deste por meio do desenvolvimento de ferramentas analíticas com interfaces amigáveis; e (c) a valorização do ambiente de conhecimento organizacional, incluindo a espontaneidade dos indivíduos para compartilhar seu conhecimento e experiências.

Melo e Araújo (2007) abordam a questão da competência informacional e sua aplicação ao contexto da GC. As autoras esclarecem que o conceito de competência informacional está diretamente relacionado às atitudes que facilitam criar e compartilhar o conhecimento, ou seja, com o aprendizado ao longo da vida (lifelong learning). As autoras discutem que a evolução histórica da competência informacional mostra que, nos países desenvolvidos, ela não tem se baseado apenas no debate científico, mas em práticas de ação política consistentes. Elas ressaltam que os países da Comunidade Comum Europeia, Canadá, Austrália, Estados Unidos e muitos outros têm compreendido a necessidade de formar cidadãos para a sociedade da informação e têm realizado investimentos importantes desde a década de 1950, evidenciando uma preocupação governamental significativa, que tem permitido o desenvolvimento de uma qualificação que envolve escolaridade eficiente e preparação eficaz para o mercado de trabalho. Contudo, o Brasil está longe dessa realidade, ainda tomando conhecimento e discutindo conceitos de competência informacional, enquanto os países desenvolvidos já discutem avaliações de programas nacionais.

Marchand e Davenport (2004) também entendem que a produção e a gestão do conhecimento variam de acordo com a cultura. Segundo os autores, há muitos exemplos na literatura, em destaque as empresas orientais (Japão, Coreia e China) que se voltam ao conhecimento tácito, inato a seus trabalhadores. Já as empresas ocidentais se encaminham ao trabalho unificado, envolvendo toda a empresa, onde todos devem assumir o papel de criadores do conhecimento. Dessa forma, promove-se uma espiral crescente de envolvimento, onde todos passam a assumir seus papéis em prol do desenvolvimento eficiente e lucrativo.

Mas um aspecto é ponto comum: a gestão do conhecimento é um tema cada vez mais pesquisado e difere da gestão da informação, sendo necessários novos olhares e pesquisas que 
permitam a sua compreensão. Nesse sentido, fez-se a opção pela apresentação de um referencial teórico que contemple a revisão da literatura nacional sobre gestão de conhecimento, objetivando expor um breve resultado sobre os estudos dos últimos anos sobre o tema, de forma a apontar o estado arte nas pesquisas científicas do assunto em questão.

Para ampliar o referencial teórico, realizou-se uma revisão dos estudos empíricos sobre GC no Brasil, na base de dados Scielo, no período entre 2003 e 2009, com as palavras-chave: "gestão" e "conhecimento". Os resultados de caráter empírico encontrados são resumidos no quadro 1 que se segue.

Quadro 1

Síntese dos estudos empíricos brasileiros sobre GC de 2003-09

\begin{tabular}{|c|c|c|}
\hline Autores & Descrição da pesquisa & Resultados \\
\hline $\begin{array}{l}\text { Colauto e Beuren } \\
\text { (2003) }\end{array}$ & $\begin{array}{l}\text { Estudo de caso em uma organização } \\
\text { hospitalar. }\end{array}$ & $\begin{array}{l}\text { Proposição de metodologia de avaliação da gestão do conheci- } \\
\text { mento. Responsabilização da alta administração na ligação entre } \\
\text { indicadores, planejamento e decisões estratégicas. }\end{array}$ \\
\hline $\begin{array}{l}\text { Vieira e Garcia } \\
(2004)\end{array}$ & $\begin{array}{l}\text { Entrevistas nas áreas de fabricação } \\
\text { de motores, manutenção, regulagem } \\
\text { de ferramentas e desenvolvimento } \\
\text { organizacional. }\end{array}$ & $\begin{array}{l}\text { Gestão do conhecimento e de competências contribuem po- } \\
\text { sitivamente com a gestão de pessoas, tornando a seleção dos } \\
\text { trabalhadores mais flexível. Redução de custos operacionais, } \\
\text { incremento na integração e comprometimento. }\end{array}$ \\
\hline $\begin{array}{l}\text { Almeida, Leal, Pinho } \\
\text { e Fagundes (2006) }\end{array}$ & $\begin{array}{l}\text { Estudo de caso em uma empresa } \\
\text { distribuidora de energia elétrica. }\end{array}$ & $\begin{array}{l}\text { Aplicação prática da GC por meio de um modelo que mapeia } \\
\text { falhas em sistema de informação. }\end{array}$ \\
\hline $\begin{array}{l}\text { Leite e Costa ( } 2006 \\
\text { e 2007) }\end{array}$ & $\begin{array}{l}\text { Pesquisa de dados secundários relati- } \\
\text { vos à produção científica no Brasil. }\end{array}$ & $\begin{array}{l}\text { Discussão sobre a aplicabilidade dos repositórios institucionais } \\
\text { como ferramenta de GC científica. Construção de um modelo } \\
\text { conceitual de GC científica no contexto acadêmico. }\end{array}$ \\
\hline Silva (2007) & $\begin{array}{l}\text { Survey para análise insumo-produto e } \\
\text { análise documental e de redes sociais } \\
\text { em aglomerado de firmas da área de } \\
\text { construção. }\end{array}$ & $\begin{array}{l}\text { Os autores concluem que: o desenvolvimento de inovações } \\
\text { pode ser uma atividade de resolução de problemas; o sistema de } \\
\text { comunicação interno nas empresas é apenas parcialmente forma- } \\
\text { lizado; as redes internas formando o capital social da empresa e } \\
\text { como partes integrantes de seu capital intelectual; as empresas } \\
\text { de construção organizam sua produção em torno de projetos } \\
\text { que, geralmente, envolvem outras empresas, organizando-se em } \\
\text { redes há muito mais tempo que outras atividades econômicas; } \\
\text { e as redes, embora importantes, não são, ainda, a preocupação } \\
\text { mais relevante das empresas. }\end{array}$ \\
\hline $\begin{array}{l}\text { Cardoso e Machado } \\
\text { (2008) }\end{array}$ & $\begin{array}{l}\text { Estudo de caso em uma universidade } \\
\text { brasileira. }\end{array}$ & $\begin{array}{l}\text { Embasadas na tese de que a GC depende cada vez mais das } \\
\text { ferramentas tecnológicas, as autoras mostram ser possível usar } \\
\text { documentos para gerar indicadores individuais e institucionais } \\
\text { de produção. Além disso, mostram que a criação de banco de } \\
\text { dados estruturados seria bastante útil tanto para a comparação } \\
\text { das diferentes instituições como também o estabelecimento de } \\
\text { políticas públicas para tais setores. }\end{array}$ \\
\hline
\end{tabular}

Continua 


\begin{tabular}{|c|c|c|}
\hline Autores & Descrição da pesquisa & Resultados \\
\hline $\begin{array}{l}\text { Santos e Amato } \\
\text { Neto (2008) }\end{array}$ & $\begin{array}{l}\text { Estudo de caso; pesquisa documental, } \\
\text { aplicação de questionário e entrevista } \\
\text { não estruturada em indústria de alta } \\
\text { tecnologia. }\end{array}$ & $\begin{array}{l}\text { As inovações estão limitadas aos conteúdos conhecidos das ciên- } \\
\text { cias e suas aplicações e estão fortemente orientadas à melhoria } \\
\text { contínua. Além disso, concluem que a indústria é o principal } \\
\text { agente das mudanças no setor, apoiada pelo comprometimento } \\
\text { da organização humana que promove a adaptação da empresa aos } \\
\text { novos requisitos do mercado. Concluíram, ainda, que neste setor } \\
\text { o foco do desenvolvimento de competências está no processo } \\
\text { de capacitação contínua. }\end{array}$ \\
\hline $\begin{array}{l}\text { Cruz e Nagano } \\
(2008)\end{array}$ & $\begin{array}{l}\text { Estudo de casos múltiplos, com entre- } \\
\text { vistas em profundidade em parques } \\
\text { tecnológicos. }\end{array}$ & $\begin{array}{l}\text { Identificação de melhores práticas de GC; apresentação de um } \\
\text { modelo de processo de desenvolvimento de pesquisa; de um } \\
\text { modelo teórico de práticas de GC em grupos de pesquisa; e os } \\
\text { desafios enfrentados pelos grupos na introdução das práticas } \\
\text { são apresentados também. Os autores relatam o predomínio da } \\
\text { conversão do tipo socialização (tácito-tácito) e apontam para o uso } \\
\text { de poucas práticas sistematizadas, ressaltando que há potencial } \\
\text { para o desenvolvimento de metodologias e ferramentas de GC } \\
\text { voltadas para as organizações que atuam em rede. }\end{array}$ \\
\hline $\begin{array}{l}\text { Gonçalves, Lima e } \\
\text { Costa (2009) }\end{array}$ & $\begin{array}{l}\text { Estudo de casos múltiplos de organi- } \\
\text { zações cooperativas. }\end{array}$ & $\begin{array}{l}\text { Identificação da presença de funções e práticas de GC, porém as } \\
\text { práticas e funções são incompletas e não caracterizam a implantação } \\
\text { de um modelo de GC. Nesse sentido, os autores reforçam a ideia de } \\
\text { que muitas organizações estão atentas para o tema, mas poucas de } \\
\text { fato conseguem implementar um modelo completo de GC. }\end{array}$ \\
\hline $\begin{array}{l}\text { Meirelles e Gomes } \\
(2009)\end{array}$ & $\begin{array}{l}\text { Estudo de caso em refinarias de } \\
\text { petróleo. }\end{array}$ & $\begin{array}{l}\text { Discutem que os métodos multicritério podem se constituir em } \\
\text { importantes instrumentos para a área de GC, desde que estejam } \\
\text { previamente modelados em sistemas que simplifiquem sua utili- } \\
\text { zação, conferindo agilidade ao processo decisório. }\end{array}$ \\
\hline $\begin{array}{l}\text { Gonzalez, Martins e } \\
\text { Toledo (2009) }\end{array}$ & $\begin{array}{l}\text { Estudo de caso em uma prestadora } \\
\text { de serviços industriais. }\end{array}$ & $\begin{array}{l}\text { O fluxo de conhecimento entre os indivíduos e entre os diversos } \\
\text { sites é intensificado devido às interações em rede, aumentando } \\
\text { o potencial da organização em promover melhoria. A proposição } \\
\text { da GC em uma organização deve estar atrelada à adaptação } \\
\text { da cultura da empresa. A estrutura em rede para a GC enfatiza } \\
\text { mais fortemente as relações horizontais que verticais. Como a } \\
\text { conectividade entre os indivíduos é uma premissa para que uma } \\
\text { organização obtenha êxito no processo de GC, os autores sugerem } \\
\text { relações entre o processo de GC com a melhoria da conectividade } \\
\text { em uma rede de organizações. }\end{array}$ \\
\hline
\end{tabular}

Fonte: Elaborado pelos autores.

\section{Método}

A grande variedade de taxionomias de tipos de pesquisa nos induziu a organizar a apresentação da metodologia de pesquisa de acordo com dois critérios básicos fornecidos por Vergara (2005): quanto aos fins e quanto aos meios. 
Quanto aos fins, a pesquisa teve característica exploratória, pois na área pretendida de análise não se verificou a existência de estudos que abordassem a discussão da importância do capital humano, das TIs e dos processos organizacionais dentro de escolas de governo numa perspectiva comparada. Quanto aos meios, a pesquisa englobou as análises bibliográfica e documental e pesquisa de campo.

A análise bibliográfica foi necessária para compreensão dos elementos que compõem as variáveis em estudo, como: GC e suas subdivisões como o conhecimento tácito e explícito, o capital humano, o processo de criação do conhecimento organizacional e as importantes interações com as tecnologias de informação. Na análise documental foram analisados os relatórios de gestão de cada uma das oito escolas de governo em conjunto com os documentos enviados pelos executivos respondentes de cada escola.

A pesquisa de campo se apresenta mediante investigação empírica realizada in loco por intermédio da aplicação de questionário aberto, enviado às escolas de governo que constituíram a amostra. A opção por esse instrumento deve-se ao fato de que ele permite mais liberdade aos respondentes em dissertar sobre os processos de gestão do conhecimento dentro das escolas, sem dizer que era inviável visitar cada uma das escolas, levando em consideração a localidade de cada uma delas. As organizações selecionadas para a composição da amostra foram aquelas consideradas mais atuantes e a intenção foi abranger, de forma sucinta, a maneira como essas instituições estrangeiras, que são congêneres da Enap, tratam ou estruturam a gestão do conhecimento organizacional mediante conjunto de processos e meios que ajudem na criação, utilização e disseminação do conhecimento dentro da organização.

A amostra foi definida pelo critério de tipicidade, pois as escolas de governo eram importantes representantes da população-alvo. As variáveis que compuseram o trabalho estão representadas no quadro 2.

$$
\text { Quadro } 2
$$

Síntese metodológica

\begin{tabular}{|c|c|c|c|c|c|}
\hline & Procedimento & Objetivo & Variáveis & Amostra & Critério de Escolha \\
\hline 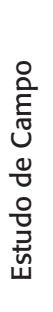 & Questionário & $\begin{array}{l}\text { Identificar os critérios } \\
\text { de criação, utilização } \\
\text { e disseminação } \\
\text { do conhecimento } \\
\text { organizacional nas } \\
\text { escolas de governo }\end{array}$ & $\begin{array}{l}\text { Capital humano; } \\
\text { tecnologia da } \\
\text { informação; } \\
\text { conhecimento } \\
\text { organizacional; } \\
\text { conhecimento tácito; e } \\
\text { conhecimento explícito }\end{array}$ & $\begin{array}{l}\text { Escolas de governo da } \\
\text { Alemanha, Portugal, } \\
\text { Argentina, Nova } \\
\text { Zelândia e Austrália, } \\
\text { França, Estados } \\
\text { Unidos da América } \\
\text { do Norte e União } \\
\text { Europeia }\end{array}$ & Tipicidade \\
\hline
\end{tabular}

Fonte: Elaborado pelos autores.

O questionário foi construído abrangendo categorias de análise — criação, utilização e disseminação — em conjunto com as variáveis contidas no quadro 1 . 
A primeira categoria de análise é a "criação" do conhecimento organizacional. Nessa categoria, Davenport e Prusak (1998) consideram cinco modos de geração do conhecimento nas organizações e que foram considerados também nesta primeira categoria de análise; são eles: aquisição (o simples fato de contratar alguém novo), recursos dedicados (criar ou estabelecer grupos para a criação de conhecimento), fusão (fusão de grupos de pessoas com conhecimento, experiência etc.), adaptação (necessidade de adaptação às alterações profundas) e redes de conhecimento (grupos de pessoas com interesses comuns que se juntam para produzir conhecimento). Nesse item foram contempladas as seguintes variáveis: capital humano (quadro próprio de funcionários e de professores); conhecimento organizacional (perenidade do ciclo de desenvolvimento do conhecimento mediante pesquisa); e conhecimentos tácito e explícito (principais ativos do processo de criação do conhecimento).

A segunda categoria de análise se refere ao processo de "utilização" do conhecimento organizacional dentro da instituição e envolve as seguintes variáveis: capital humano (principais responsáveis pela troca de conhecimento tácito mediante congressos, discussões, debates etc.); conhecimentos tácito e explícito (ativos que estão presentes tanto nas discussões, nos congressos e nos debates quando nas revistas e nos processos organizacionais); e tecnologia da informação (responsável pela organização desses conhecimentos em forma de dados e informações). Essa segunda categoria, também conhecida como codificação ou armazenamento, é uma das fases mais importantes do processo de GC, pois, de acordo com Silva (2004:192), "trata-se de tornar o conhecimento acessível àqueles que dele necessitam e no momento em que dele necessitam". Também neste momento o papel da tecnologia da informação é igualmente importante por ser o principal dispositivo que amplia o alcance e acelera a velocidade de transferência do conhecimento (Silva, 2004). De acordo com Castro (1999), a tecnologia pode influenciar quantitativa e qualitativamente o processo de construção do conhecimento, imprimindo-lhe novas características.

A terceira e última categoria de análise diz respeito à "disseminação" do conhecimento organizacional por meio das seguintes variáveis: tecnologia da informação (que auxilia na contenção dos conhecimentos tácito e explícito); e processos organizacionais (os processos, também conhecidos como workflow, quando bem implementados e consolidados dentro da organização, auxiliam a manutenção do conhecimento).

Mais uma vez a tecnologia da informação permeia o processo de GC, agora na terceira categoria de análise, auxiliando o processo mediante papel de infraestrutura (Silva, 2004). O processo organizacional de fluxo de dados e de informação também é importante para garantir todo o ciclo de criação, utilização e manutenção do conhecimento, pois, de acordo com Silva (2004:220), "explicita o conhecimento que está embutido no processo".

Bock e Marca (1995) afirmam que o fluxo de informação (processos) fornece suporte essencial aos processos organizacionais, e o fluxo passa de pessoa para pessoa, de lugar para lugar e de tarefa para tarefa.

Na primeira etapa de resultados da pesquisa será apresentado o estudo de campo com a análise das condições da GC nas principais escolas de governo do mundo e, logo em seguida, 
as conclusões do estudo de Jesus (2006) — estudo de caso da escola de governo, Fundação Escola Nacional de Administração Pública (Enap).

Os resultados de Jesus (2006) foram necessários como ponto de partida para o mapeamento dos critérios que caracterizaram o ciclo de criação, utilização e disseminação do conhecimento organizacional, de modo a propiciar certa padronização para a análise comparada entre as oito instituições.

Tem-se por questão norteadora de trabalho que a comparação dos critérios de criação, divulgação e manutenção do conhecimento organizacional pode viabilizar o desenho de uma estrutura organizacional mais eficiente na gestão do conjunto de processos e meios mais importantes para a criação, utilização e disseminação do conhecimento dentro de organizações de ensino como as escolas de governo.

\section{Resultados}

Este tópico apresentará um histórico resumido sobre as sete instituições pesquisadas, salientando as atividades e/ou área de atuação que as caracterizam como centros de treinamento e/ou formação de servidores públicos (escolas de governo).

Neste tópico temos como objetivo fornecer base para o debate comparativo dos critérios que abrangem as categorias de análise do conhecimento organizacional (criação, utilização e disseminação).

\subsection{Argentina - Instituto Nacional de la Administración Pública (Inap)}

O Instituto Nacional de la Administración Pública (Inap) é uma escola de governo semelhante à Enap do Brasil. Procura estabelecer, de forma pluralista, a formação de líderes sociais e políticos capazes de projetar, debater e construir uma sociedade com justiça e equidade. Seus objetivos buscam contribuir com a formação do pensamento estratégico nacional; a promoção de redes de integração social, intercâmbio, conhecimento e experiência entre líderes políticos e sociais; o estabelecimento de debates e reflexões; e a facilitação da aquisição dos conhecimentos e das habilidades requeridos para a boa gestão das políticas públicas.

O Instituto Nacional de la Administración Pública (Inap) atua em quatro frentes:

a) Programa de investigação sobre gestão pública

、 Planejamento, coordenação e execução de pesquisas que contribuam com o desenvolvimento do conhecimento e da gestão pública;

จ Realização de estudos e pesquisas vinculados à gestão pública, orientados a maximizar os princípios de transparência, serviço, eficiência, equidade e controle do social; e

จ Identificação e difusão dos debates e tendências no que diz respeito à problemática da gestão pública no país e no mundo. 
b) Cooperação e assistência técnica

- Apoio metodológico e/ou participação em pesquisas realizadas por outros organismos públicos, tutoria de projetos de pesquisa de pós-graduação em administração pública e participação ativa em reuniões técnicas; e

v Cooperação no desenvolvimento de pesquisas com universidades, institutos de pesquisa, organizações da sociedade civil local, regional e internacional.

c) RedMund

v Participação na Rede Nacional de Centros Acadêmicos dedicados ao estudo da gestão em governos locais.

d) Publicações

- Difundir estudos e experiências que possam apoiar os processos de transformação da gestão pública.

O Inap atua em pesquisa, informação e formação dos servidores no âmbito da gestão pública. Porém, há algumas peculiaridades que o tornam diferente da Enap do Brasil. A grande maioria dos funcionários que atuam na instituição é do quadro de funcionários de carreira que trabalham como suporte de especialistas contratados.

É importante salientar que uma parte significativa desses funcionários de carreira atua como docentes próprios do Inap nas atividades institucionais de formação, porém dentro de seus respectivos âmbitos de atuação, o que não acontece na Enap.

Outra característica que os diferencia são os convênios firmados em tempo integral pelo Inap com grande número de universidades ${ }^{4}$ nacionais e estrangeiras.

Com relação à gestão do conhecimento (GC), de acordo com o diretor nacional do Inap, José Luis Tesoro, as atividades cotidianas das áreas técnicas do instituto sustentam-se sobre um conjunto de princípios que os ajudam a gerir o conhecimento. Porém, acentua o diretor, esse conjunto de princípios não é qualificado formalmente como "política", nem mesmo é denominado "gestão do conhecimento", mas está presente e plenamente vigente no trabalho setorial e intersetorial das equipes da escola. Ele fortalece sua opinião afirmando que o conjunto desses princípios e critérios equivale a uma "política de gestão do conhecimento", que é cotidianamente tangível na atuação do Inap.

\footnotetext{
${ }^{4}$ Universidad de Buenos Aires, Universidad Nacional del Centro de la Provincia de Buenos Aires, Universidad Nacional del Comahue, Universidad Nacional de Córdoba, Universidad Nacional de Cuyo, Universidad Nacional de Entre Ríos, Universidad Nacional de General San Martín, Universidad Nacional de General Sarmiento, Universidad Nacional de La Matanza, Universidad Nacional de la Plata, Universidad Nacional del Litoral, Universidad Nacional de Lomas de Zamora, Universidad Nacional de Mar del Plata, Universidad Nacional de Misiones, Universidad Nacional del Noroeste de la Pcia. de Buenos Aires, Universidad Nacional de Quilmes, Universidad Nacional de Río Cuarto, Universidad Nacional de Rosario, Universidad Nacional de Salta, Universidad Nacional de Santiago del Estero, Universidad Nacional de Villa María, Universidad de San Andrés, Universidad Tecnológica Nacional, Universidad Caece, Universidad Austral, Universidad Católica de Córdoba, Universidad Católica de Santa Fe, Universidad Católica de Santiago del Estero, Universidad de Belgrano, Universidad del Aconcagua e Universidad de Morón.
} 
Os princípios são:

จ objetivos e prioridades claramente formulados e difundidos;

$\checkmark$ desenvolvimento de ambiente de respeito, confiança e sinergia por parte de todos os integrantes;

- conhecimento, por parte de todos os integrantes, das características, do estado e dos avanços relevantes de todos os projetos — de formação, pesquisa e informação — que estão em desenvolvimento dentro da instituição;

v promoção de intercâmbio, da discussão e da discussão cruzada entre aqueles que participam em distintas funções, equipes e projetos institucionais;

v sistematização e difusão, entre os integrantes da instituição, dos resultados, dos achados e das aprendizagens emergentes de cada projeto institucional; e

v participação dos integrantes nas redes externas e comunidades práticas — presenciais ou virtuais - consideradas relevantes para as atividades institucionais de formação, pesquisa e informação.

\subsection{Portugal - Instituto de Administração Pública (INA)}

O Instituto de Administração Pública (INA) é uma instituição pública dotada da missão de contribuir, por meio da formação, da investigação científica e da assessoria técnica, para a modernização da administração pública e para valorização de seus servidores. Essa missão, assim como a da Enap, implica o desenvolvimento de ações de formação interdisciplinar, de investigação e desenvolvimento, de intercâmbio e cooperação.

As principais vertentes de atividades do INA são as seguintes:

a) Formação - O INA trabalha com a formação continuada do servidor público português, com a possibilidade de montar cursos sob medida e também com a formação daqueles civis que necessitam de preparo para o início de funções no âmbito das carreiras de técnico superior e das carreiras administrativas da função pública. Os cursos de especialização, cerca de 20, visam proporcionar formação estruturante, alinhada com a vertente de modernização da administração pública. Os congressos e conferências sobre o tema gestão pública são ações executadas constantemente para garantir o debate e a circulação de informações. Em termos de e-learning, o INA oferece ainda formação em e-learning, através da internet, que permite percursos formativos flexíveis. Alguns dos cursos presenciais tiram partido das potencialidades pedagógicas desta forma de aprendizagem, adotando um modelo de blended learning, em que o e-learning é usado como complemento da formação presencial.

b) Estudos e investigação - Os estudos e a investigação científica são centrados no apoio à formulação das políticas públicas. O espaço está aberto para funcionários seniores da administração pública e professores universitários interessados em realizar estudos neste âmbito de atuação. 
c) Consultoria — Diferente da Enap, o INA trabalha também com consultorias em sua área de competência.

d) Publicação - O INA possui uma revista (Cadernos de Ciência e Legislação) que abrange a análise de políticas públicas.

e) Cooperação internacional - Importante cooperação bilateral e multilateral é firmada com o Timor, países da UE, da Europa Central e de Leste, China e América Latina, envolvendo, muitas vezes, organismos internacionais (Comissão Europeia, Banco Mundial, PNUD etc.).

Assim como o Inap da Argentina e a Enap do Brasil, o INA não se diferencia muito na forma de atuação. É uma espécie de escola de governo que tem como missão a capacitação, ora continuada, ora de formação, mas sempre visando à aprendizagem do servidor público com o propósito de suprir a administração pública com capital humano qualificado.

Seu quadro de funcionários abriga uma porcentagem de $65 \%$ de servidores de carreira e 35\% de especialistas contratados. Essa porcentagem ajuda na gestão e manutenção do capital humano dentro da organização, evitando a grande rotatividade de funcionários, comum na Enap.

No que diz respeito ao quadro de professores, o instituto não possui um quadro fixo, buscando-os no mercado, assim como a Enap o faz, mas diferentemente do Inap da Argentina, que utiliza seus especialistas para ministrar aulas.

Quando se pensa em cooperação técnica, assim como na Enap e no Inap, no INA existe tal cooperação, porém somente com instituições internacionais, tais como: Warsaw School of National Administration, London School of Economics and Political Science, Soros Foundations Network, Blalystok School of Public Administration e European Institute of Lodz.

Sobre a existência de alguma política de GC na instituição, garantiu-se que a política existe e é desenvolvida com um grupo de técnicos e investigadores, envolvidos em um projeto de avaliação e prospectiva da administração pública, até 2015, sob a coordenação de Valadares Tavares, presidente do INA. Importante salientar esse envolvimento do presidente, pois assim as políticas tendem a ser absorvidas pelo corpo gerencial e técnico mais rapidamente (Nonaka e Takeuchi, 1997).

\subsection{Austrália e Nova Zelândia - The Australia and New Zealand School of Government}

A escola de governo da Nova Zelândia e Austrália (ANZSOG) foi criada por um consórcio de gover$\operatorname{nos}^{5}$ (cinco governos) e universidades, ${ }^{6}$ caracterizando-se como instituição sem fins lucrativos.

\footnotetext{
${ }^{5}$ Comunidade da Austrália, o governo de Nova Zelândia e os governos dos Estados do novo Wales do sul, Queensland e Victoria (Commonwealth of Australia, the New Zealand Government, and the State Governments of New South Wales, Queensland and Victoria).

${ }^{6}$ As universidades são as seguintes: Australian National University, Griffith University, Melbourne Business School Limited, Monash University, The University of Melbourne, The University of New South Wales, The University of Queensland, The University of Sydney, University of Canberra e Victoria University of Wellington.
} 
Esse consórcio reconhece que um dos mais relevantes desafios para todos os governos do século XXI é melhorar o aprofundamento e a amplitude das políticas públicas e investir na educação de ponta daqueles que são destinados a ser líderes no setor público. Os programas executivos de curta e média duração e os mestrados da ANZSOG são feitos sob medida, única e exclusivamente para as necessidades dos governos da Austrália e da Nova Zelândia, fazendo uso da experiência dos seus líderes acadêmicos, políticos e servidores públicos e também do mundo. A ANZSOG é uma escola com muitos campi e de diversos governos. Essas características fazem dela um centro de estudos pós-graduado para servidores públicos de dinâmica muito peculiar em relação às escolas de governo nos moldes tradicionais como a Academia Federal, Enap, Inap, ENA e INA. Desta forma, a ANZSOG consegue oferecer cursos em diversos campi, ampliando seu alcance/impacto, a partir do momento que um mesmo curso pode ser oferecido em diversas localidades para um número maior de servidores públicos.

O interesse desta escola de governo é oferecer educação e treinamento para os novos líderes do setor público mediante uma gama flexível de programas de pós-graduação e de cursos executivos que subsidiem a construção de novas políticas e pesquisas dentro da esfera pública. O interesse também circunda o desenvolvimento da agenda de pesquisa para o fortalecimento das habilidades de governo nos três níveis de federação: âmbito federal, estadual e local, assim como o Inap e o INA.

A questão da GC dentro da organização é interessante, pois a escola é bastante diferente das outras no que diz respeito aos seus funcionários e ao quadro de professores. Enquanto a maioria das escolas de governo estudadas contrata professores no mercado e outras fazem uso de seus próprios funcionários especialistas na docência ou até mesmo um misto dessas duas situações, a ANZSOG possui uma estrutura muito pequena de funcionários da própria organização, porém absorve uma gama de funcionários e de professores muito intensa das 10 universidades que a compõem. Logo, é possível encontrar dentro dessa escola uma estrutura muito fortalecida e com requinte de universidade.

Essa estrutura favorece a criação do conhecimento organizacional e, consequentemente, a GC, pois os professores e funcionários de carreira tornam-se perenes na organização, facilitando o projeto da escola de governo dentro dos governos em que atua. Essa condição viabiliza mais facilmente atingir a missão organizacional, pois o quadro de professores especialistas consegue criar e desenvolver cursos com as reais necessidades dos governos mediante pesquisas perenes e estudos dirigidos, facilitando o êxito da missão organizacional.

A estrutura de funcionários da ANZSOG é marcada por um quadro de professores que inclui decano, diretores acadêmicos de estudos de caso, colaboradores de pesquisa, professores presidentes da cadeira de gestão pública e administração pública, entre outros.

Existe, ainda, um quadro de professores adjuntos que provêm do consórcio das universidades que contribuem com os programas da ANZSOG e outro quadro de professores diretamente vinculados à escola de governo que fazem parte também do consórcio de universidades. Computam-se, também, um quadro administrativo de funcionários e um quadro de colaboradores, que fazem parte das mais diversas áreas de governo, como ministros, secretários, professores, entre outros. 
Essa estrutura, segundo a coordenadora geral administrativa, Anne Measday, garante à escola a possibilidade de graduar seus alunos com títulos de pós-graduação. Essa situação é similar à que houve na Enap do Brasil, que necessitava de parcerias com as universidades para fornecer títulos de pós-graduação aos servidores que fizessem cursos dessa natureza. ${ }^{7}$

Quando questionada sobre a GC na organização, Anne Measday configurou o estabelecimento da escola por meio do consórcio, enfatizando a necessidade de manutenção constante da relação de parceria para garantir a continuidade das pesquisas e, consequentemente, do provimento das necessidades governamentais por meio da capacitação de novos líderes do setor público.

\subsection{Alemanha - Bundesakademie für öffentliche Verwaltung - Federal Academy of Public Administration}

A Academia Federal de Administração Pública da Alemanha é um centro de treinamento da esfera federal de governo. Trabalha diretamente com a administração federal, a indústria e a universidade, além de ser responsável pela melhora do rendimento produtivo do serviço público mediante a prática adotada, o treinamento avançado.

Esse centro de treinamento do governo federal alemão diferencia-se do Inap, da ANZSOG e do INA, respectivamente da Argentina, da Nova Zelândia e Austrália e de Portugal, pelo fato de que os dois centros latino-americanos e o centro da Oceania são institutos de treinamento da esfera federal, regional e local. A Enap do Brasil possui a mesma peculiaridade da Academia Federal alemã, pois é um centro de treinamento do servidor público federal.

A Academia Federal de Administração Pública tem sua área de atuação focada na ação produtiva da administração pública, logo, suas áreas de atuação estão vinculadas ao treinamento para desenvolvimento da carreira pública; treinamento para supervisores e gerentes; integração europeia e cooperação internacional para desenvolvimento e troca de conhecimentos; e treinamento em tecnologia da informação.

O treinamento e desenvolvimento de carreiras (training for career advancement) tem como finalidade ajudar na qualificação dos servidores para prepará-los na absorção de altas demandas de trabalho. O treinamento de supervisores e gerentes (training for supervisors and managers) está preocupado com a modernização da administração pública por meio do desenvolvimento das habilidades em gerir equipes orientadas para resultados. A integração europeia e o crescimento da cooperação internacional (European integration and international co-operation) demandam novas habilidades e conhecimentos em diversas áreas da administração pública federal, sendo necessária a disseminação de seminários diversos para trocas de

\footnotetext{
${ }^{7}$ Condição não mais necessária após o ano de 2004, quando o Ministério da Educação forneceu à escola o credenciamento para a oferta de programas e cursos de pós-graduação lato sensu em suas áreas de competência durante cinco anos (Portaria no 11 , de 14 de janeiro de 2005).
} 
programas com a Comissão Europeia e instituições parceiras que provêm debates e trocas de conhecimento e experiência. A modernização da administração pública federal necessita de treinamento na área da tecnologia da informação. Por isso a Academia Federal tem diversos cursos que enfatizam a área, fornecendo suporte para o e-government, BundOnline 2005.

De acordo com Renate Plücken-Opolka, coordenador da Academia Federal, a instituição é parte do Ministério do Interior e, por essa razão, os funcionários que nela atuam não constituem um corpo próprio. São funcionários de carreira do próprio ministério. Esses funcionários concebem, planejam e organizam aproximadamente 1.100 cursos com 20 mil participantes anualmente.

Essa característica dá à Academia Federal uma perenidade na estrutura organizacional, sendo possível gerir a criação e o compartilhamento do conhecimento de forma mais gradual e expressiva, sem quebrar o ciclo de criação do conhecimento. O reflexo dessa forte estrutura já garante à Academia Federal seus primeiros passos no uso de nova mídia instrucional — a implementação da plataforma do conhecimento ou do sistema de gestão da aprendizagem —, que é acompanhada por várias medidas (www.lernplattform-bakoev.bund.de).

O quadro de professores da Academia Federal não é fixo e o critério de contratação é embasado na experiência acadêmica e profissional na administração pública, aspecto em que se assemelha bastante à Enap do Brasil.

Quando questionado sobre as parcerias com universidades, Renate Plücken-Opolka respondeu que há uma única cooperação, com a University of Cologne, com a qual desenvolveu a plataforma do conhecimento, mas afirmou que a Academia Federal possui uma gama de conselheiros, que abarca as áreas de ciências, economia e administração pública, para o caso de necessidade de professores.

\subsection{Estados Unidos da América - John Kennedy School of Government - Harvard University}

A Escola de Governo John Kennedy — John Kennedy School of Government — foi o nome dado à então estabelecida Graduate School of Public Administration, em 1937, na Universidade de Harvard, por meio de uma doação de Lucius N. Littauer, em 1936.

Desde então foram sendo estabelecidos vários e importantes programas de estudos na área pública, como o Littauer Fellowship Program, que se transformou, em pouco tempo, no Mid-Career Master in Public Administration Program (MC/MPA).

Anos mais tarde, o programa cresceu e a preocupação com as questões dos países em desenvolvimento também, sendo criado o Mason Fellows, voltado para líderes dos países em desenvolvimento (emergentes). Nos anos 1960, a faculdade lançou um programa de políticas públicas (public policy curriculum) mais baseado em economia e estudos analíticos que nos princípios tradicionais de administração pública. Este último programa transformou-se em um Programa de Mestrado em Políticas Públicas, com dois anos de duração, marcando a presença da instituição no âmbito público. Nos dias de hoje, a Kennedy School tem evoluído e 
se tornado uma das mais renomadas instituições de pesquisa em ciência social, abarcando 15 centros e institutos e mais de 12 programas de estudos.

A missão da organização é esforçar-se em promover o maior entendimento e cooperação entre o mundo acadêmico e o mundo da política e das relações políticas. Para isso é oferecida aos estudantes uma gama de oportunidades, tais como fóruns, programas de graduação, grupos de estudos liderados por visitantes e colaboradores residentes, conferências para garantir interação e trocas de conhecimentos com as pessoas que fazem parte da política e das relações públicas.

Nota-se que a Kennedy School não é apenas uma escola de governo, mas, sim, um grande centro de discussões, que reúne cerca 14 grandes institutos e mais de 12 programas de ensino no âmbito da administração pública dentro da Universidade de Harvard. ${ }^{8}$

O formato de universidade dá à escola certa garantia no investimento em longo prazo nos próprios funcionários. Assim, a escola consegue ter um quadro próprio de professores especialistas, que garantem o desenvolvimento de trabalho duradouro e de impacto na formação de líderes do setor público mundial. Essa situação garante o atendimento da missão da organização, pois garante perenidade no quadro de professores e pesquisadores que dominam o debate e promovem constantes ajustes para o alcance das necessidades do público-alvo, sendo reconhecida mundialmente.

De acordo com o professor adjunto em políticas públicas, Peter Zimmerman, a Kennedy School possui cerca de 120 professores que atuam em período integral e chegarão até a aposentadoria e mais de 300 pesquisadores e funcionários de apoio da própria organização.

A escola, assim como as outras estudadas no presente trabalho, também possui acordos com diversas outras escolas ou centros de estudos de outras universidades, porém o respondente das questões, Peter Zimmerman, não as citou.

Essa condição favorável do quadro perene de funcionários da escola faz com que seja garantida uma grande gama de mudanças e inovações no âmbito da GC para os quadros de funcionários de apoio e de professores. Ou seja, criam-se bases de dados de todos os tipos para a facilitação da socialização das informações e desenvolvem-se fontes de pesquisas constantes (centros de discussões, diria até de socialização, externalização, combinação e internalização) para a melhora constante da criação de conhecimento organizacional da instituição.

\subsection{União Europeia - European Institute of Public Administration (Eipa)}

O Instituto Europeu de Administração Pública - European Institute of Public Administration (Eipa) — não é denominado escola de governo, mas, sim, centro de treinamentos e pesquisas sobre administração pública e políticas europeias. Essa mesma denominação é dada

\footnotetext{
${ }^{8}$ A Universidade de Harvard é formada pelos seguintes centros: Faculty of Arts and Sciences; Faculty of Medicine; Harvard Business School; Graduate School of Design; Harvard Divinity School; Harvard Graduate School of Education; John F. Kennedy School of Government; Harvard Law School; Radcliffe Institute for Advanced Study; e Harvard School of Public Health.
} 
à Academia Federal de Administração Pública da Alemanha, o que as diferem nesse aspecto do restante das organizações aqui estudadas.

Criado em 1981, o Eipa é apoiado pelos estados-membros da União Europeia e diretamente pela Comissão Europeia, possuindo sua sede em Maastricht, Holanda, e três descentralizações localizadas nas cidades de Luxemburgo, em Luxemburgo, Barcelona, na Espanha, e Milão, na Itália.

Sua função primordial é fornecer treinamento para melhorar e desenvolver as habilidades e capacidades dos oficiais públicos no tratamento das políticas públicas e relações europeias, oferecendo treinamento, pesquisa e serviços de consultoria. ${ }^{9}$

As atividades do Eipa incluem treinamento, consultoria, pesquisa, informação e documentação. O instituto também publica trabalhos de pesquisa, resultados de pesquisas e boletins trimestrais. A estrutura do Instituto Europeu é bem diferente das outras organizações já analisadas até o momento. Tem cerca de 135 funcionários, 90 destes alocados na sede do Eipa em Maastricht e os outros 45 funcionários distribuídos por Luxemburgo, Barcelona e Milão.

Torna-se complicado, ao falar em GC, entender uma estrutura tão descentralizada e com 93\% de funcionários contratados e sem carreira dentro da organização, enquanto os outros 7\% são funcionários cedidos das administrações nacionais (governo federal) para o Eipa, por períodos entre dois e três anos, segundo Paul Geurten, do Departamento Pessoal.

Dessa forma, o Eipa torna-se a instituição mais atípica do universo apresentado na pesquisa até o momento, com cerca de $45 \%$ de seu quadro de funcionários composto por professores que permanecem na instituição por poucos anos. Apenas alguns chegam aos 20 anos de trabalho, de acordo com Paul Geurten.

A forma de atuação da organização não é muito propícia a um ambiente de criação de conhecimento organizacional, pois as pessoas estão dispersas e não possuem perenidade no grupo, dificultando o processo de socialização e criação do conhecimento que ajuda a instituição a atingir suas metas e objetivos. Paul Geurten afirmou que não há nenhum grupo dentro da instituição que zele pela GC, pois eles somente ministram treinamentos e seminários na área de atuação de cada um de seus especialistas.

Assim como as outras organizações de treinamento de servidores públicos estudadas até o momento, o Eipa possui acordos com duas universidades: a Maastricht University, na Holanda, e a University of Trier, na Alemanha.

\subsection{França - École Nationale d'Administration (ENA)}

A École Nationale d'Administration (ENA) francesa foi a fonte de inspiração do ex-embaixador Sérgio Paulo Rouanet na criação da Enap do Brasil. Nos anos 1980, período em que foi

\footnotetext{
${ }^{9}$ Das instituições estudadas até o presente momento, somente o INA de Portugal fornece, como serviços da escola, a consultoria.
} 
concebida a pesquisa, Rouanet considerou a ENA francesa como o exemplo que melhor representava a realidade brasileira.

Criada em 1945 pelo governo provisório do então general de Gaulle com o intuito de formar os quadros superiores da administração pública, a ENA nasceu com o objetivo de preparar para o Estado uma elite de dirigentes, provendo-o de pessoas com capacidade de pensá-lo e transformá-lo.

Hoje, a ENA oferece treinamento polivalente e internacional, já que está aberta a toda diversidade cultural existente, pois estrangeiros, funcionários públicos e civis podem prestar as provas para o ingresso à carreira oferecida pela escola. Todos os alunos, após admissão, adquirem salário e status de servidor público, obtendo treinamento variado, que abarca o direito público, a economia, a gestão pública, o orçamento e as finanças, as questões internacionais e europeias e os estudos de línguas estrangeiras.

A missão da escola é preparar os servidores públicos para a tendência chamada globalização, de tal forma que se torne possível o controle e a antecipação dos problemas governamentais surgidos no mundo. Para isso a ENA tem de trabalhar como uma escola de ensino aplicado, de orientação internacional e que desenvolve carreira e pesquisa. Como escola de ensino aplicado - a missão é fornecer treinamento interministerial para os futuros agentes públicos seniores mediante treinamento de 27 meses, que acontecem de duas maneiras distintas: período de internato (12 meses); e período de estudos (15 meses). Como escola que é orientada internacionalmente, tem treinado nos últimos anos mais de 2 mil estudantes internacionais de mais de 100 nações. Além do mais, a ENA mantém ativas cooperações administrativas com diversos parceiros internacionais que colaboram com transferências de experiências mediante diversos seminários. No que diz respeito ao desenvolvimento de carreira e pesquisa, a ENA não fornece apenas treinamentos para o desenvolvimento de servidores públicos seniores, mas também conduz pesquisa na área das ciências administrativas.

As pesquisas conduzidas pela organização estão focadas no desenvolvimento de uma série de seminários sobre os maiores problemas do setor público; no encorajamento de projetos de pesquisas sobre problemas correntes na administração pública; e na multiplicação de comparações sobre os diferentes sistemas administrativos internacionais.

De acordo com Hélène Mazeran, chefe do Departamento sobre América, a ENA possui cerca de $75 \%$ do quadro de funcionários no regime de carreira e os outros $25 \%$ são contratados. Essa situação possibilita, de acordo com a abordagem do trabalho, a chance de especular sobre a condição da criação do conhecimento organizacional dentro da instituição, pois há perenidade. Logo, a alta porcentagem de funcionários de carreira pode prover boa disseminação e homogeneização de informações em ambiente organizacional em que as carreiras são duradouras, garantindo o cumprimento da missão.

O mesmo não se pode dizer sobre o quadro de professores na ENA, uma vez que ela não tem um quadro de professores. A Enap do Brasil assemelha-se muito à escola francesa, pois foi criada a partir de seu modelo e, neste aspecto, também não possui quadro de professores, sendo todos contratados no mercado. 
Como todas as outras instituições estudadas até o presente momento, verifica-se na ENA a importância da troca de conhecimentos mediante relacionamento com outras instituições de ensino. Dessa forma, a ENA promove acordos de cooperação com as mais diversas escolas congêneres: Kennedy School of Government, na Universidade de Harvard; The School of Public Environmental Affairs, em Indiana, região americana, e com outros institutos ou escolas de administração pública ou academias diplomáticas em que são conduzidos programas profissionais de treinamento.

As três categorias, em conjunto (criação, divulgação e manutenção), formam um ambiente propício para o estabelecimento de uma política de GC, porém Hélène Mazeran não soube responder sobre o assunto, quando questionada.

\section{Discussão}

As variáveis de pesquisa (capital humano, conhecimentos tácito e explícito, tecnologia da informação e processos organizacionais) analisadas no estudo de caso sobre a Enap contribuíram para as seguintes conclusões:

a) a rotatividade do capital humano interfere no processo de criação e desenvolvimento do conhecimento organizacional. Isso porque os níveis de variação do capital humano na Enap são expressivamente altos até o ano pesquisado, 2005. Essa situação, de acordo com Nonaka e Takeuchi (1997), não contribui com o processo de criação, utilização e disseminação do conhecimento organizacional;

b) um quadro de servidores públicos bem estruturado, no que diz respeito à carreira sólida, e bons salários poderiam contribuir para a manutenção e perenidade da política da organização;

c) um quadro mínimo de professores seria de notável importância para o desenvolvimento de pesquisas e alinhamento do projeto pedagógico da escola com a missão organizacional;

d) a TI diminui a perda de conhecimento na organização mesmo com a alta rotatividade de funcionários, hipótese confirmada segundo os conceitos de Marchand e Davenport (2004) e Silva (2004);

e) parte dos funcionários é resistente aos fluxos de atividades da organização.

Dessa forma, mapearam-se os critérios que se julgaram melhor representantes do conjunto de processos e meios mais importantes para criar, utilizar e disseminar conhecimento dentro de uma organização de ensino de servidores públicos. O objetivo é desenhar uma estrutura organizacional que contribua com mais eficiência no que diz respeito à criação, utilização e disseminação do conhecimento organizacional em uma escola de governo.

De acordo com a figura seguinte, o processo de desenvolvimento do conhecimento organizacional se encontra dividido em três categorias de análise, já exemplificadas e expli- 
cadas na metodologia de trabalho deste estudo: criação, divulgação e manutenção do conhecimento. Nota-se que os quatro modos de conversão do conhecimento ${ }^{10}$ citados por Nonaka e Takeuchi (1997) estão contidos no processo (figura a seguir). Por esse motivo, entende-se serem importantes a análise e a comparação dos critérios entre as escolas.

Figura

Modos de conversão do conhecimento

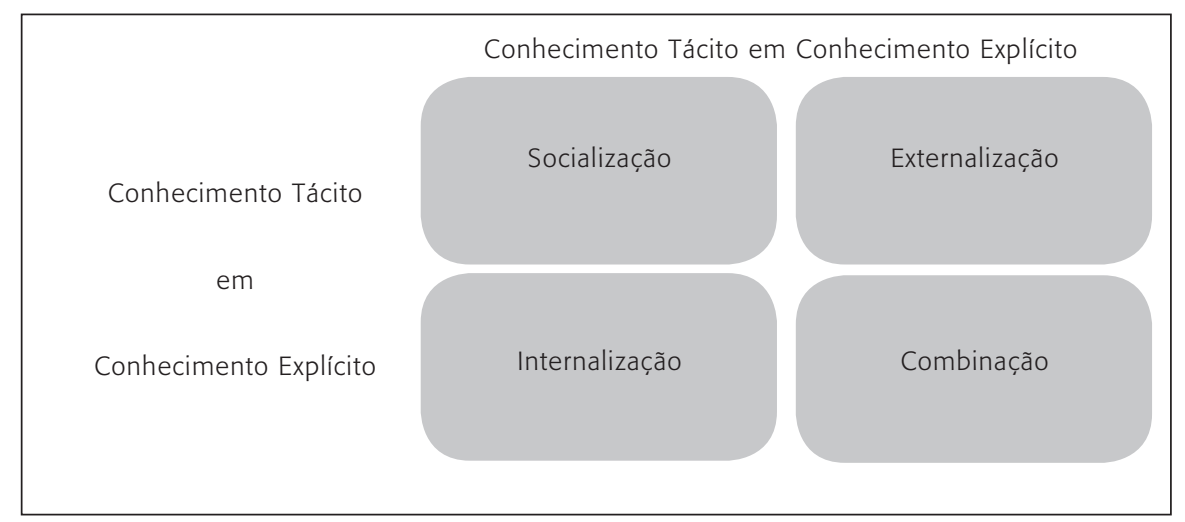

Fonte: Elaborado pelos autores.

\subsection{Critério da criação}

A primeira etapa do ciclo do conhecimento é a categoria "criação", que foi dividida em quatro critérios definidos pelo estudo de caso da Enap. Os critérios identificados como relevantes no estudo de caso são os seguintes: pesquisa; departamento de estudos de caso; quadro próprio de funcionários; e quadro próprio de professores.

O quadro próprio de funcionários garante a perenidade dos processos organizacionais e, consequentemente, o período de socialização do conhecimento tácito entre os funcionários da organização escolar. Essa interação criará mais conhecimento organizacional, que será externalizado em conceitos explícitos. Esse ciclo, quando completo, seguido pela externalização, combinação e internalização, gera acréscimo de conhecimento na organização, segundo Nonaka e Takeuchi (1997). Dessa forma, o quadro de funcionários bem estruturado, com carreira bem definida e bons salários, possivelmente contribuirá com o ciclo inteiro.

\footnotetext{
${ }^{10}$ A socialização do conhecimento é um processo de compartilhamento de experiências entre as pessoas, em que a experiência é o instrumento central de transferência de conhecimentos. Após o conhecimento compartilhado, originar-se-á mais conhecimento, porém, em conceitos explícitos, este momento é conhecido como externalização. A combinação é o momento em que os conhecimentos explícitos são trocados pelo capital humano (funcionários) de uma organização, mediante reuniões, debates e redes de comunicação computadorizadas (e-mail, msn, programas de gerenciamento de projetos, entre outros), e esse processo pode gerar novos conhecimentos, que serão incorporados pelo capital humano por meio da internalização.
} 
O quadro próprio de professores possivelmente trará mais consistência ao projeto de desenvolvimento de pesquisas conjuntamente com o departamento de estudo de casos, fornecendo novos conhecimentos para o ciclo de conhecimento organizacional (Silva, 2004).

De acordo com o quadro 3, dos quatro critérios levantados pelo estudo de caso na primeira etapa da categoria - criação - , quando são confrontados os resultados de todas as escolas, identificam-se somente três escolas de governo que possuem mais de dois critérios (Instituto Nacional de la Administración Pública, da Argentina; Australia and New Zealand School of Government, da Austrália e Nova Zelândia; e John Kennedy School of Government, dos Estados Unidos da América).

Quadro 3

Primeira etapa do ciclo de desenvolvimento do conhecimento organizacional: criação

\begin{tabular}{|c|c|c|c|c|c|c|}
\hline Escolas de governo & Nacionalidade & Pesquisa & $\begin{array}{c}\text { Departamento } \\
\text { de estudos de } \\
\text { caso }\end{array}$ & $\begin{array}{c}\text { Quadro } \\
\text { próprio de } \\
\text { funcionários }\end{array}$ & $\begin{array}{c}\text { Quadro } \\
\text { próprio de } \\
\text { professores }\end{array}$ & $\begin{array}{l}\text { Total de } \\
\text { critérios por } \\
\text { escola de } \\
\text { governo }\end{array}$ \\
\hline $\begin{array}{l}\text { Fundação Escola } \\
\text { Nacional de } \\
\text { Administração Pública }\end{array}$ & Brasil & SIM & NÃO & SIM & NÃO & 2 \\
\hline $\begin{array}{l}\text { Instituto de } \\
\text { Administração Pública }\end{array}$ & Portugal & SIM & NÃO & SIM & NÃO & 2 \\
\hline $\begin{array}{l}\text { Federal Academy of } \\
\text { Public Administration }\end{array}$ & Alemanha & NÃO & NÃO & SIM & NÃO & 1 \\
\hline $\begin{array}{l}\text { Australia and New } \\
\text { Zealand School of } \\
\text { Government }\end{array}$ & $\begin{array}{c}\text { Nova Zelândia e } \\
\text { Austrália }\end{array}$ & SIM & SIM & SIM & SIM & 4 \\
\hline $\begin{array}{l}\text { European Institute of } \\
\text { Public Administration }\end{array}$ & União Europeia & NÃO & NÃO & SIM & NÃO & 1 \\
\hline $\begin{array}{l}\text { John Kennedy School } \\
\text { of Government }\end{array}$ & $\begin{array}{c}\text { Estados Unidos } \\
\text { da América }\end{array}$ & SIM & SIM & SIM & SIM & 4 \\
\hline $\begin{array}{l}\text { École Nationale } \\
\text { d'Administration }\end{array}$ & França & SIM & NÃO & SIM & NÃO & 2 \\
\hline $\begin{array}{l}\text { Instituto Nacional de la } \\
\text { Administración Pública }\end{array}$ & Argentina & SIM & NÃO & SIM & SIM & 3 \\
\hline
\end{tabular}

Fonte: Elaborado pelos autores.

\subsection{Critério da utilização}

Na segunda etapa do ciclo, categoria "utilização", os critérios identificados no estudo de caso foram: (a) revistas, publicações, cadernos de debates etc.; (b) congressos, debates, discussões 
etc.; (c) interoperabilidade/integração dos sistemas de informação; e (d) processos internos consolidados e ativos.

Mediante pesquisa, a escola tem possibilidade de criar conhecimento e, por meio das publicações, congressos e debates, ela poderá socializar o conhecimento criado. Esse processo é conhecido como externalização e combinação, defendido por Nonaka e Takeuchi (1997).

Os sistemas de informação são o meio de viabilização de todo o processo de desenvolvimento do conhecimento organizacional, pois dessa forma os processos internos consolidam-se em conjunto com o capital humano (Edvinsson e Malone, 1998).

Confrontando-se os critérios de todas as oito escolas de governo estudadas, apenas a Federal Academy of Public Administration e a Fundação Escola Nacional de Administração Pública possuem três critérios (quadro 4).

\section{Quadro 4}

Segunda etapa do ciclo de desenvolvimento do conhecimento organizacional: utilização

\begin{tabular}{|c|c|c|c|c|c|c|}
\hline $\begin{array}{l}\text { Escolas de } \\
\text { governo }\end{array}$ & Nacionalidade & $\begin{array}{c}\text { Revistas, } \\
\text { publicações, } \\
\text { cadernos de } \\
\text { debates etc. }\end{array}$ & $\begin{array}{l}\text { Congressos, } \\
\text { debates, } \\
\text { discussões } \\
\text { etc. }\end{array}$ & $\begin{array}{c}\text { Interopera- } \\
\text { bilidade/Integração } \\
\text { dos sistemas de } \\
\text { informação }\end{array}$ & $\begin{array}{l}\text { Processos } \\
\text { internos } \\
\text { consolidados } \\
\text { e ativos }\end{array}$ & $\begin{array}{c}\text { Total de } \\
\text { critérios } \\
\text { por escola } \\
\text { de governo }\end{array}$ \\
\hline $\begin{array}{l}\text { Fundação Escola } \\
\text { Nacional de } \\
\text { Administração } \\
\text { Pública }\end{array}$ & Brasil & SIM & SIM & SIM & NÃO & 3 \\
\hline $\begin{array}{l}\text { Instituto de } \\
\text { Administração } \\
\text { Pública }\end{array}$ & Portugal & SIM & SIM & SIM & SIM & 4 \\
\hline $\begin{array}{l}\text { Federal Academy } \\
\text { of Public } \\
\text { Administration }\end{array}$ & Alemanha & NÃO & SIM & SIM & SIM & 3 \\
\hline $\begin{array}{l}\text { Australia and New } \\
\text { Zealand School of } \\
\text { Government }\end{array}$ & $\begin{array}{l}\text { Nova Zelândia } \\
\text { e Austrália }\end{array}$ & SIM & SIM & SIM & SIM & 4 \\
\hline $\begin{array}{l}\text { European } \\
\text { Institute of Public } \\
\text { Administration }\end{array}$ & União Europeia & SIM & SIM & SIM & SIM & 4 \\
\hline $\begin{array}{l}\text { John Kennedy } \\
\text { School of } \\
\text { Government }\end{array}$ & $\begin{array}{c}\text { Estados Unidos } \\
\text { da América }\end{array}$ & SIM & SIM & SIM & SIM & 4 \\
\hline $\begin{array}{l}\text { École Nationale } \\
\text { d'Administration }\end{array}$ & França & SIM & SIM & SIM & SIM & 4 \\
\hline $\begin{array}{l}\text { Instituto } \\
\text { Nacional de la } \\
\text { Administración } \\
\text { Pública }\end{array}$ & Argentina & SIM & SIM & SIM & SIM & 4 \\
\hline
\end{tabular}

Fonte: Elaborado pelos autores. 


\subsection{Critério da disseminação}

A terceira e última etapa do ciclo do conhecimento, a categoria "disseminação", tem como critérios relevantes identificados no estudo de caso os seguintes: (a) manutenção de memória técnica organizacional; (b) sistemas de tecnologia da informação; (c) intercâmbio; e (d) processos internos consolidados e ativos.

A memória técnica, quando sistematizada e disponibilizada pelos sistemas de TI mediante processos internos consolidados e ativos, torna-se forte aliada no desenvolvimento do conhecimento organizacional, pois completa o ciclo de conversão do conhecimento com a combinação e internalização do conhecimento (Davenport e Prusak, 1998).

O intercâmbio é uma forma de transferência de conhecimento que é muito interessante para o processo, pois os conhecimentos podem ser trocados entre organizações congêneres.

Das oito escolas de governo estudadas, apenas uma possui dois critérios dos quatro classificados, a Enap (quadro 5).

Quadro 5

Terceira etapa do ciclo de desenvolvimento do conhecimento organizacional: disseminação

\begin{tabular}{|c|c|c|c|c|c|c|}
\hline Escolas de governo & Nacionalidade & $\begin{array}{l}\text { Manutenção } \\
\text { de memória } \\
\text { técnica } \\
\text { organizacional }\end{array}$ & $\begin{array}{l}\text { Sistemas de } \\
\text { tecnologia da } \\
\text { informação }\end{array}$ & Intercâmbio & $\begin{array}{l}\text { Processos } \\
\text { internos } \\
\text { consolidados } \\
\text { e ativos }\end{array}$ & $\begin{array}{l}\text { Total de } \\
\text { critérios por } \\
\text { escola de } \\
\text { governo }\end{array}$ \\
\hline $\begin{array}{l}\text { Fundação Escola } \\
\text { Nacional de } \\
\text { Administração } \\
\text { Pública }\end{array}$ & Brasil & NÃO & SIM & SIM & NÃO & 2 \\
\hline $\begin{array}{l}\text { Instituto de } \\
\text { Administração } \\
\text { Pública }\end{array}$ & Portugal & SIM & SIM & SIM & SIM & 4 \\
\hline $\begin{array}{l}\text { Federal Academy of } \\
\text { Public Administration }\end{array}$ & Alemanha & SIM & SIM & SIM & SIM & 4 \\
\hline $\begin{array}{l}\text { Australia and New } \\
\text { Zealand School of } \\
\text { Government }\end{array}$ & $\begin{array}{l}\text { Nova Zelândia } \\
\text { e Austrália }\end{array}$ & SIM & SIM & SIM & SIM & 4 \\
\hline $\begin{array}{l}\text { European Institute of } \\
\text { Public Administration }\end{array}$ & União Europeia & SIM & SIM & SIM & SIM & 4 \\
\hline $\begin{array}{l}\text { John Kennedy } \\
\text { School of } \\
\text { Government }\end{array}$ & $\begin{array}{l}\text { Estados Unidos } \\
\text { da América }\end{array}$ & SIM & SIM & SIM & SIM & 4 \\
\hline $\begin{array}{l}\text { École Nationale } \\
\text { d’Administration }\end{array}$ & França & SIM & SIM & SIM & SIM & 4 \\
\hline $\begin{array}{l}\text { Instituto Nacional } \\
\text { de la Administración } \\
\text { Pública }\end{array}$ & Argentina & SIM & SIM & SIM & SIM & 4 \\
\hline
\end{tabular}

Fonte: Elaborado pelos autores. 


\subsection{Discussão a partir dos critérios identificados pela pesquisa}

O estudo identificou alguns pontos importantes sobre os critérios de desenvolvimento do conhecimento organizacional nas escolas de governo. Como pontos positivos, todas as escolas de governo possuem os seguintes critérios: (a) quadro próprio de funcionários (porém alguns não muito bem estruturados); (b) congressos, debates, discussões etc.; (c) interoperabilidade/integração dos sistemas de informação; (d) sistemas de tecnologia da informação; e (e) intercâmbio. O gráfico a seguir viabiliza a identificação das escolas detentoras dos critérios de desenvolvimento do conhecimento organizacional de maneira resumida.

Como pontos negativos são apontados os critérios alocados no item "criação". São os menos utilizados pelas escolas de governo em geral: (a) das oito escolas de governo, seis não possuem departamento de estudo de caso; (b) cinco não possuem quadro próprio de professores; e (c) duas não possuem área de pesquisa. Em relação aos critérios alocados no item "utilização", os pontos negativos são: (a) uma escola de governo não possui, como forma de divulgação e dispersão do conhecimento organizacional, revistas, publicações e cadernos de debates; e (b) uma não possui os processos internos consolidados e ativos. Como critérios alocados no item "disseminação" destaca-se como ponto negativo o fato de que uma escola não possui manutenção e disseminação de memória técnica organizacional e processos internos consolidados e ativos (A Enap instituiu, por meio da Portaria Enap no 25, de 16 de março de 2005, o Arquivo Geral da Enap, que assegura a proteção e o acesso às informações produzidas e recebidas no desenvolvimento das funções e atividades da escola.).

Gráfico

Quantidade de critérios identificados por escola de governo

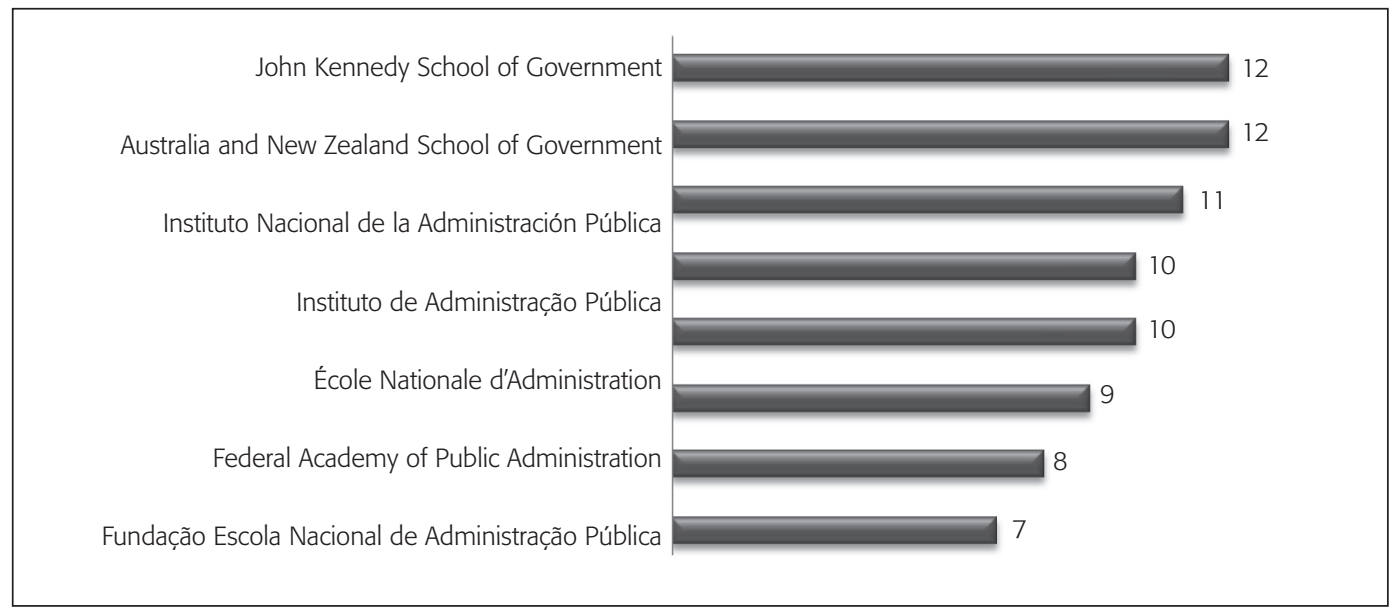

Fonte: Elaborado pelos autores. 


\section{Considerações finais}

O crescimento da valorização do conhecimento pode ser considerado inevitável, uma vez que o fluxo de investimentos em pessoas e a utilização plena da inteligência dos trabalhadores dissemina-se pelo mundo e converge para uma economia baseada no conhecimento (Colauto e Beuren, 2003).

De acordo com o estudo desenvolvido, evidenciaram-se os pontos positivos e negativos do ciclo de conhecimento organizacional das oito escolas de governo. Por um lado, a comparação oferece um conhecimento interessante de aspectos que podem ser aperfeiçoados no modelo brasileiro. Por outro lado, é preciso considerar que as instituições objeto de comparação têm escopos diferentes. Nesse sentido, ressalta-se que a instituição alemã funciona como um grande centro de treinamento e capacitação operacional e gerencial das burocracias estatais, a JFK School of Government e a ENA são centros formadores de elites intelectuais para o serviço público e privado. No caso da França, a grande maioria dos altos executivos do setor privado é proveniente da ENA — enarques - e, da mesma forma, a JFK é um centro de recrutamento para o setor privado que tem ou pretende ter relações com entidades estatais.

Essas diferenças são inerentes à própria concepção dessas escolas e aos propósitos que cada uma atende e é fundamental que se leve em conta tais discrepâncias quando se faz um estudo comparativo. Contudo, guardadas as especificidades de cada escola, a comparação permanece sendo válida como um panorama de possibilidades e caminhos que conduzem a diferentes resultados em termos de qualificação do público-alvo das escolas de cada um desses países.

Como uma das limitações deste trabalho, é preciso apontar o uso do questionário aberto respondido pelos próprios centros pesquisados. Se, por um lado, esse tipo de instrumento de coleta de dados era necessário em um estudo exploratório e que buscava conhecer realidades distintas inseridas em culturas específicas, por outro lado, esse tipo de instrumento fundamenta-se em perguntas que têm um inevitável grau de generalização, o que prejudica uma análise mais objetiva dos atributos e deficiências de cada centro.

Como decorrência dessa limitação, a segunda hipótese de trabalho (se a tecnologia de informação pode ajudar o processo de desenvolvimento do conhecimento organizacional) não pôde ser detalhada da forma como idealizado, com informações que descrevessem a capacidade tecnológica das instituições, o acesso a bancos de dados de base digital, bibliotecas eletrônicas, processos de tele-educação etc.

O estudo de comparação teve o intuito de fornecer subsídios para auxiliar as organizações públicas em seus processos de desenvolvimento do conhecimento organizacional e, principalmente, de criar uma estrutura mais inteligente de gestão desse conhecimento em uma escola de governo.

Para isso, a colaboração das escolas de governo foi essencial, fornecendo informações precisas e detalhadas sobre suas estruturas e seus recursos humanos (capital humano).

Dessa forma, verificou-se que o INA, de Portugal, a Academia Federal de Administração Pública, da Alemanha, o Eipa, da União Europeia, e a ENA, da França, atuam da mesma ma- 
neira que a Enap, visto que não utilizam quadro de professores próprios, recrutando-os por períodos predeterminados no mercado.

Essa atuação fornece flexibilidade na escolha do profissional, porém dificulta o relacionamento definidor dos interesses da escola, muitas vezes até mesmo pelo fato de não possuir um projeto pedagógico definido, podendo o profissional não atender às necessidades esperadas pela organização, com relação a seus cursos. Esse é um dos problemas enfrentados pela Enap e também um foco de desvantagem no atendimento da missão organizacional.

O Inap, da Argentina, age de forma mais distinta. Utiliza seus próprios servidores especialistas nas áreas de atuação da organização para ministrar as disciplinas. Esse modo de atuação garante maior probabilidade de atendimento aos interesses da organização, pois o professor, também funcionário, constrói o ciclo do conhecimento organizacional, aperfeiçoando, a todo momento, o processo de aprendizagem, mediante aperfeiçoamento do projeto pedagógico em conjunto com as necessidades da organização e/ou governo.

A Escola de Governo John Kennedy - John Kennedy School of Government — é, de fato, uma escola voltada para formação do alto escalão de servidores públicos de todo o mundo, porém possui uma característica muito diferente dos outros centros, ou seja, é uma universidade. Assim, possui quadro de professores e funcionários próprios com a opção de terceirização do quadro administrativo.

Essa condição de universidade garante-lhe discussões em volta de toda temática que envolve o desenvolvimento dos cursos, ao redor das necessidades dos governos, chegando a grande produtividade científica e, consequentemente, ao atendimento da missão organizacional. Assim, o nível de criação e manutenção do conhecimento na organização torna-se muito poderoso, fazendo dela uma das mais renomadas escolas de governo do mundo.

Entende-se, dessa forma, que o ciclo se desenvolve muito bem na John Kennedy e no Inap, de acordo com o conceito de Nonaka e Takeuchi (1997), como pode ser visto na figura. Isso porque os dois centros possuem perenidade nos principais quadros de funcionários da instituição, a condição necessária para seu desenvolvimento. Essa perenidade é garantida, pois a grande maioria dos funcionários contratados é da área meio, na qual os processos são puramente processuais.

O mesmo acontece com a escola de governo da Austrália e Nova Zelândia. Ela é formada por um consórcio de universidades e governos, ou seja, seu quadro de servidores é de ambos, porém perene, pois é composto por funcionários de carreira.

É interessante a forma de estruturação dessa escola, pois possui um quadro administrativo advindo do consórcio, entre eles um quadro de professores próprios, provenientes das universidades. A situação dessa escola garante uma escola de governo totalmente ligada às necessidades dos governos, para os quais fornece serviços e professores acadêmicos que pesquisam e estruturam cursos altamente voltados para a necessidade dos governos do consórcio. O ciclo de geração do conhecimento e compartilhamento de Nonaka e Takeuchi (1997) acaba por ser cumprido em ambiente tão favorável como esse.

Mediante o desenvolvimento de pesquisa comparativa, pôde-se demonstrar que, para a estrutura organizacional de uma escola de governo manter um ciclo de desenvolvimento 
do conhecimento organizacional saudável e rentável para a organização, é necessária a perenidade do capital humano, corpo docente institucional minimamente estruturado, processos organizacionais bem definidos e ambiente focado na pesquisa e na alta produtividade acadêmica/profissional. Esse comparativo entre as grandes escolas de governo de vários países oferece um rico referencial para correção de rumos e para evolução de entidades focadas no ensino governamental.

\section{Referências}

ALMEIDA, Dagoberto A. de et al. Gestão do conhecimento na análise de falhas: mapeamento de falhas através de sistema de informação. Produção [on-line], v. 16, n. 1, p. 171-188, 2006.

ALVARENGA NETO, Rivadávia C.D. de. Gestão do conhecimento em organizações: proposta de mapeamento conceitual e integrativo. Tese (doutorado em ciência da informação) — Escola de Ciência da Informação, Universidade Federal de Minas Gerais, Belo Horizonte, 2005.

ALVARENGA NETO, Rivadávia C.D. de; BARBOSA, Ricardo R.; PEREIRA, Heitor J. Gestão do conhecimento ou gestão de organizações da era do conhecimento? Um ensaio teórico-prático a partir de intervenções na realidade brasileira. Perspectivas em Ciência da Informação [on-line], v. 12, n. 1, p. 5-24, 2007.

BOCK, Geoffrey; MARCA, David. Designing groupware. Nova York: McGraw-Hill, 1995.

CARDOSO, Olinda N.P.; MACHADO, Rosa T.M. Gestão do conhecimento usando data mining: estudo de caso na Universidade Federal de Lavras. Revista de Administração Pública [on-line], v. 42, n. 3, p. 495-528, 2008.

CASTRO, Márcia N.M. Aprendizagem na organização e novas tecnologias aplicadas à educação a distância. Belo Horizonte: Programa de Pós-Graduação em Ciência da Informação, 1999.

COLAUTO, Romualdo D.; BEUREN, Ilse M. Proposta para avaliação da gestão do conhecimento em entidade filantrópica: o caso de uma organização hospitalar. Revista de Administração Contemporânea [on-line], v. 7, n. 4, p. 163-185, 2003.

CRUZ, Cláudia A.; NAGANO, Marcelo S. Gestão do conhecimento e sistemas de informação: uma análise sob a ótica da teoria de criação do conhecimento. Perspectivas em Ciência da Informação [on-line], v. 13, n. 2, p. 88-106, 2008.

DAVENPORT, Thomas; PRUSAK, Laurence. Conhecimento empresarial: como as organizações gerenciam seu capital intelectual. Rio de Janeiro: Campus, 1998.

EDVINSSON, Leif; MALONE, Michael S. Capital intelectual: descobrindo o valor real de sua empresa pela identificação de seus valores. Tradução de Roberto Galman; revisão técnica de Petros Kata Lifós. São Paulo: Makron Books, 1998.

FACHIN, Geisy R.B. et al. Gestão do conhecimento e a visão cognitiva dos repositórios institucionais. Perspectivas em Ciência da Informação [on-line], v. 14, n. 2, p. 220-236, 2009. 
GONCALVES, Luciano C.; LIMA, Edson P. de; COSTA, Sérgio E.G. da. Um estudo sobre a adoção de práticas de gestão do conhecimento em organizações cooperativas. Produção [on-line], v. 19, n. 1, p. 163-189, 2009.

GONZALEZ, Rodrigo V.D.; MARTINS, Manoel F.; TOLEDO, José C. de. Gestão do conhecimento em uma estrutura organizacional em rede. Ciência da Informação [on-line], v. 38, n. 1, p. 57-73, 2009.

JESUS, Anderson M. de. The importance of maintenance of the human capital in the preservation of organizational knowledge: an evaluation of the National School of Public Administration - Enap. In: INTERNATIONAL CONFERENCE IN LOMONOSOV MOSCOW STATE UNIVERSITY SCHOOL OF PUBLIC ADMINISTRATION — PUBLIC ADMINISTRATION IN THE XXI CENTURY: TRADITIONS AND INNOVATIONS, Moscou, 2006. p. 211-219.

LEITE, Fernando C.L.; COSTA, Sely M. de S. Gestão do conhecimento científico: proposta de um modelo conceitual com base em processos de comunicação científica. Ciência da Informação [online], v. 36, n. 1, p. 92-107, 2007.

LEITE, Fernando C.L.; COSTA, Sely M. de S. Repositórios institucionais como ferramentas de gestão do conhecimento científico no ambiente acadêmico. Perspectivas em Ciência da Informação [on-line], v. 11, n. 2, p. 206-219, 2006.

LIMA, Karina K. de; AMARAL, Daniel C. Práticas de gestão do conhecimento em grupos de pesquisa da rede Instituto Fábrica do Milênio. Gestão da Produção [on-line], v. 15, n. 2, p. 291-305, 2008.

MARCHAND, Donald A.; DAVENPORT, Thomas H. (Org.). Dominando a gestão da informação. Tradução de Carlo Gabriel Porto Bellini e Carlos Alberto Sileira Netto Soares. Porto Alegre: Bookman, 2004.

MEIRELLES, Carmen L. de A.; GOMES, Luiz F.A.M. O apoio multicritério à decisão como instrumento de gestão do conhecimento: uma aplicação à indústria de refino de petróleo. Pesquisa Oper [on-line], v. 29, n. 2, p. 451-470, 2009.

MELO, Ana V.C. de; ARAÚJO, Eliany A. de. Competência informacional e gestão do conhecimento: uma relação necessária no contexto da sociedade da informação. Perspectivas em Ciência da Informação [on-line], v. 12, n. 2, p. 185-201, 2007.

NONAKA, Ikujiro; TAKEUCHI, Hirotaka. Criação de conhecimento na empresa: como as empresas japonesas geram a dinâmica da inovação. Tradução de Ana Beatriz Rodrigues e Priscilla Martins Celeste. 7. ed. Rio de Janeiro: Campus, 1997.

PACHECO, Regina S. Escolas de governo: tendências e desafios - Enap-Brasil em perspectiva comparada. Revista do Serviço Público, Brasília, n. 2, p. 35-53, 2000.

SANTOS, Isabel C. dos; AMATO NETO, João. Gestão do conhecimento em indústria de alta tecnologia. Produção [on-line], v. 18, n. 3, p. 569-582, 2008.

SILVA, Antônio B. de O. e. O cluster da construção em Minas Gerais e as práticas de colaboração e de gestão do conhecimento: um estudo das empresas da Região Metropolitana de Belo Horizonte (MG). 
Tese (doutorado em ciência da informação) — Escola de Ciência da Informação, Universidade Federal de Minas Gerais, Belo Horizonte, 2007.

SILVA, Ricardo V. da. Gestão de empresas na era do conhecimento. São Paulo: Serinews Editora, 2004.

SOMMER, Barbara; SOMMER, Robert. A practical guide to behavioral research: tools and techniques. 4. ed. Nova York: Oxford University Press, 1997.

SOUTO, Patricia N. Knowledge management: uncovering risky gaps underlying the criticisms and moving to another perspective. Ciência da Informação [on-line], v. 36, n. 2, p. 64-73, Aug. 2007.

TEECE, David J. Strategies for managing knowledge assets: the role of firm structure and industrial context. Long Range Planning, v. 33, p. 35-54, 2000.

VERGARA, Silvia C. Projetos e relatórios de pesquisa em administração. 6. ed. São Paulo: Atlas, 2005.

VICK, Thais; NAGANO, Marcelo S.; SANTOS, Fernando C.A. Aportes da gestão da informação para a criação de conhecimento em equipes de inovação. Perspectivas em Ciência da Informação [on-line], 2009, v. 14, n. 2, p. 204-219, 2009.

VIEIRA, Adriane; GARCIA, Fernando C. Gestão do conhecimento e das competências gerenciais: um estudo de caso na indústria automobilística. RAE Eletrônica [on-line], v. 3, n. 1, 2004.

WILSON, Tom D. The nonsense of "knowledge management". Information Research, v. 8, n. 1, Oct. 2002.

Anderson Macedo de Jesus é consultor especialista em Objetivos de Desenvolvimento do Milênio no United Nations Development Programme (UNDP). E-mail: andemacj@gmail.com.

Luciana Mourão é professora do mestrado em psicologia da Universidade Salgado de Oliveira (Universo). E-mail: mourao.luciana@gmail.com. 